Acta Crystallographica Section E

\section{Structure Reports}

Online

ISSN 1600-5368
H. S. Yathirajan, ${ }^{a}$

T. V Sreevidya, ${ }^{b}$ B. Narayana,

B. K. Sarojini ${ }^{c}$ and Michael Bolte ${ }^{\text {* }}$

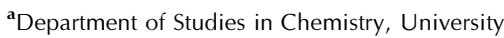
of Mysore, Manasagangotri, Mysore 570 006, India, ${ }^{\mathbf{b}}$ Department of Chemistry, Mangalore University, Mangalagangotri 574 199, India, cDepartment of Chemistry, P.A. College of Engineering, Nadupadavu, Mangalore 574153, India, and Institut für Anorganische Chemie, J. W. Goethe-Universität Frankfurt, Max-vonLaue-Strasse 7, 60438 Frankfurt/Main, Germany

Correspondence e-mail:

bolte@chemie.uni-frankfurt.de

\section{Key indicators}

Single-crystal X-ray study

$T=173 \mathrm{~K}$

Mean $\sigma(\mathrm{C}-\mathrm{C})=0.002 \AA$

$R$ factor $=0.049$

$w R$ factor $=0.139$

Data-to-parameter ratio $=18.7$

For details of how these key indicators were automatically derived from the article, see http://journals.iucr.org/e.

\title{
(2E)-3-(4-Butoxyphenyl)-1-(4-chlorophenyl)- prop-2-en-1-one
}

The central double bond in the title molecule, $\mathrm{C}_{19} \mathrm{H}_{19} \mathrm{ClO}_{2}$, is trans configured. Geometric parameters are in normal ranges.

\section{Comment}

$\alpha, \beta$-Unsaturated ketones, in which the double bond is adjacent to the carbonyl group, have been used as starting materials for the synthesis of various chemicals, including plastics, resins, pesticides, dyes and pharmaceuticals (Opdyke, 1973). Chalcones and the corresponding heterocyclic analogs are valuable intermediates in organic synthesis (Dhar, 1981) and show numerous biological effects (Opletalova \& Sedivy, 1999; Dimmock et al., 1999). In addition, with appropriate subsitutuents, chalcones are a class of non-linear optical (NLO) materials (Fichou et al., 1988; Butcher et al., 2006; Harrison et al., 2006; Sarojini et al., 2006). Among several organic compounds reported to have NLO properties, chalcone derivatives are recognized materials because of their excellent blue-light transmittance and good crystallization ability. They provide a necessary configuration to show NLO properties, with two planar rings connected through a conjugated double bond (Goto et al., 1991; Uchida et al., 1998; Tam et al., 1989; Indira et al., 2002). Recently, we have reported the crystal structures of a series of such compounds (Yathirajan et al., 2006a,b; Yathirajan, Narayana et al., 2006; Yathirajan, Ashalatha et al., 2006). In a continuation of this work, and also considering the importance of flavanoid analogs, we have determined the crystal structure of the title compound, (I). In fact, the title compound crystallizes in a centrosymmetric space group so does not exhibit NLO properties.<smiles>COc1ccc(/C=C/C(=O)c2ccc(Cl)cc2)cc1</smiles>

(I)

The molecular structure of (I) is shown in Fig. 1. Bond lengths and angles can be regarded as normal (Allen et al., 1987). The central double bond is trans configured. The dihedral angle between the two benzene rings is $42.53(6)^{\circ}$. The central ring (C21-C26) is almost coplanar with the double bond $\left[\mathrm{C} 2-\mathrm{C} 3-\mathrm{C} 21-\mathrm{C} 26=9.9(2)^{\circ}\right]$ and the chlorophenyl ring is twisted out of the plane of the double bond by $31.8(2)^{\circ}$.

\section{Experimental}

The title compound was synthesized according to a method reported in the literature (Furniss et al., 1989), in a yield of $80 \%$. The
Received 23 November 2006 Accepted 23 November 2006 
compound was purified by recrystallization from ethanol. Crystals were grown by slow evaporation of a solution of (I) in acetone (m.p. $333-335 \mathrm{~K})$. Analysis found (calculated) (\%) for $\mathrm{C}_{19} \mathrm{H}_{19} \mathrm{ClO}_{2}: \mathrm{C} 72.90$ (72.49), H 6.05 (6.08).

\section{Crystal data}

$$
\begin{aligned}
& \mathrm{C}_{19} \mathrm{H}_{19} \mathrm{ClO}_{2} \\
& M_{r}=314.79 \\
& \text { Triclinic, } P \overline{1} \\
& a=5.9580(6) \AA \\
& b=11.6745(12) \AA \\
& c=12.6433(12) \AA \\
& \alpha=106.346(9)^{\circ} \\
& \beta=94.975(7)^{\circ} \\
& \gamma=103.112(8)^{\circ}
\end{aligned}
$$

$$
\begin{aligned}
& V=811.14 \text { (14) } \AA^{3} \\
& Z=2 \\
& D_{x}=1.289 \mathrm{Mg} \mathrm{m}^{-3} \\
& \text { Mo } K \alpha \text { radiation } \\
& \mu=0.24 \mathrm{~mm}^{-1} \\
& T=173 \text { (2) K } \\
& \text { Plate, light yellow } \\
& 0.32 \times 0.28 \times 0.11 \mathrm{~mm}
\end{aligned}
$$

\section{Data collection}

Stoe IPDS-II two-circle diffractometer

$\omega$ scans

Absorption correction: multi-scan (MULABS; Spek, 2003; Blessing, 1995)

$T_{\min }=0.928, T_{\max }=0.977$

\section{Refinement}

Refinement on $F^{2}$

$R\left[F^{2}>2 \sigma\left(F^{2}\right)\right]=0.049$

$w R\left(F^{2}\right)=0.139$

$S=1.02$

3725 reflections

199 parameters

$\mathrm{H}$-atom parameters constrained

$$
\begin{gathered}
w=1 /\left[\sigma^{2}\left(F_{\mathrm{o}}{ }^{2}\right)+(0.0818 P)^{2}\right. \\
+0.1402 P] \\
\text { where } P=\left(F_{\mathrm{o}}{ }^{2}+2 F_{\mathrm{c}}{ }^{2}\right) / 3 \\
(\Delta / \sigma)_{\max }<0.001 \\
\Delta \rho_{\max }=0.38 \mathrm{e} \AA^{-3} \\
\Delta \rho_{\min }=-0.37 \mathrm{e}^{-3}
\end{gathered}
$$

$\mathrm{H}$ atoms were found in a difference map but they were refined using a riding model, with $\mathrm{C}-\mathrm{H}=0.95 \AA$ for aromatic and methylene groups and $\mathrm{C}-\mathrm{H}=0.98 \AA$ for methyl groups. $U_{\text {iso }}(\mathrm{H})$ values were set at $1.2 U_{\text {eq }}(\mathrm{C})\left[1.5 U_{\text {eq }}(\right.$ methyl C) $]$.

Data collection: $X$-AREA (Stoe \& Cie, 2001); cell refinement: $X$ $A R E A$; data reduction: $X$ - $A R E A$; program(s) used to solve structure: SHELXS97 (Sheldrick, 1997); program(s) used to refine structure: SHELXL97 (Sheldrick, 1997); molecular graphics: PLATON (Spek, 2003); software used to prepare material for publication: SHELXL97 and PLATON.

One of the authors (BKS) thanks AICTE, Government of India, for financial assistance through the Career Award for Young Teacher's Scheme.

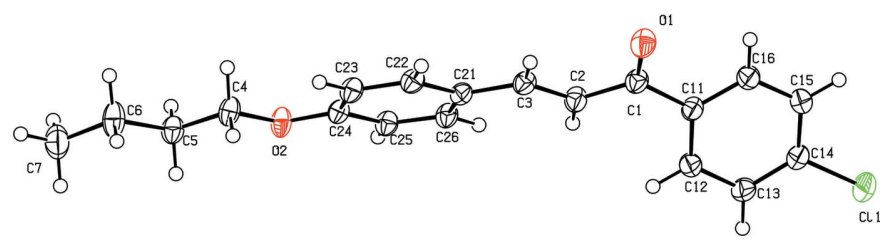

Figure 1

The molecular structure of (I) with the atom numbering; displacement ellipsoids are drawn at the $50 \%$ probability level.

\section{References}

Allen, F. H., Kennard, O., Watson, D. G., Brammer, L., Orpen, A. G. \& Taylor, R. (1987). J. Chem. Soc. Perkin Trans. 2, pp. S1-19.

Blessing, R. H. (1995). Acta Cryst. A51, 33-38.

Butcher, R. J., Yathirajan, H. S., Anilkumar, H. G., Sarojini, B. K. \& Narayana, B. (2006). Acta Cryst. E62, o1659-o1661.

Dhar, D. N. (1981). The Chemistry of Chalcones and Related Compounds. New York: Wiley Interscience.

Dimmock, J. R., Elias, D. W., Beazely, M. A. \& Kandepu, N. M. (1999). Curr. Med. Chem. 6, 1125-1149.

Fichou, D., Watanabe, T., Takeda, T., Miyata, S., Goto, Y. \& Nakayama, M. (1988). Jpn J. Appl. Phys. 27, L429-L430.

Furniss, B. S., Hannaford, A. J., Smith, P. W. G. \& Tatchell, A. R. (1989). Vogel's Textbook of Practical Organic Chemistry, 5th ed, p. 1034. New York: Longman Group UK Ltd.

Goto, Y., Hayashi, A., Kimura, Y. \& Nakayama, M. (1991). J. Cryst. Growth, 108, 688-698.

Harrison, W. T. A., Yathirajan, H. S., Ashalatha, B. V., Bindya, S. \& Narayana, B. (2006). Acta Cryst. E62, o4164-o4165.

Indira, J., Karat, P. P. \& Sarojini, B. K. (2002). J. Cryst. Growth, 242, 209-214.

Opdyke, D. L. J. (1973). Food Cosmet. Toxicol. 11, 1011-1081.

Opletalova, V. \& Sedivy, D. (1999). Ceska Slov. Farm. 48, 252-255.

Sarojini, B. K., Narayana, B., Ashalatha, B. V., Indira, J. \& Lobo, K. J. (2006). J. Cryst. Growth, 295, 54-59.

Sheldrick, G. M. (1997). SHELXS97 and SHELXL97. University of Göttingen, Germany.

Spek, A. L. (2003). J. Appl. Cryst. 36, 7-13.

Stoe \& Cie (2001). X-AREA. Stoe \& Cie, Darmstadt, Germany.

Tam, W., Guerin, B., Calabrese, J. C. \& Stevenson, S. H. (1989). Chem. Phys. Lett. 154, 93-96.

Uchida, T., Kozawa, K., Sakai, T., Aoki, M., Yoguchi, H., Abduryim, A. \& Watanabe, Y. (1998). Mol. Cryst. Liq. Cryst. 315, 135-140.

Yathirajan, H. S., Ashalatha, B., Narayana, B., Bindya, S. \& Bolte, M. (2006). Acta Cryst. E62, o4551-04553.

Yathirajan, H. S., Narayana, B., Ashalatha, B., Sarojini, B. K. \& Bolte, M. (2006). Acta Cryst. E62, o4440-o4441.

Yathirajan, H. S., Sarojini, B. K., Narayana, B., Bindya, S. \& Bolte, M. (2006a). Acta Cryst. E62, o3629-03630.

Yathirajan, H. S., Sarojini, B. K., Narayana, B., Bindya, S. \& Bolte, M. (2006b). Acta Cryst. E62, o3631-03632. 